\title{
Discarded Carbon-Zinc Batteries as Source of an Efficient Heterogeneous Fenton-Like Catalyst Employed to Degrade Organic Molecules in an Aqueous Medium
}

\author{
A. Valadares, S. F. Resende, I. M. F. de Oliveira, R. Augusti* \\ Departamento de Química, Universidade Federal de Minas Gerais, Belo Horizonte, Brazil \\ Email: *augusti.rodinei@gmail.com
}

How to cite this paper: Valadares, A., Resende, S.F., de Oliveira, I.M.F. and Augusti, R. (2019) Discarded Carbon-Zinc Batteries as Source of an Efficient Heterogeneous Fenton-Like Catalyst Employed to Degrade Organic Molecules in an Aqueous Medium. Green and Sustainable Chemistry, 9, 94-103.

https://doi.org/10.4236/gsc.2019.93007

Received: July 17, 2019

Accepted: August 19, 2019

Published: August 22, 2019

Copyright $\odot 2019$ by author(s) and Scientific Research Publishing Inc. This work is licensed under the Creative Commons Attribution International License (CC BY 4.0).

http://creativecommons.org/licenses/by/4.0/

\begin{abstract}
The present work evaluates the feasibility of using the raw material collected from discarded zinc-carbon batteries as heterogeneous catalyst to degrade the dye Indigo Carmine in an aqueous solution. Besides the evident environmental application, this work also presents an economic alternative for the production of new catalysts used to remediate polluted waters. For this, discarded carbon-zinc batteries were gathered, disassembled and their anodic paste collected. After acidic treatment and calcination at $500^{\circ} \mathrm{C}$, characterization measurements, i.e. flame atomic absorption spectroscopy (FAAS), nitrogen sorption, $\mathrm{X}$-ray diffraction (XRD) and scanning electron microscopy (SEM), revealed that the so-obtained material consisted mainly of $\mathrm{ZnMn}_{2} \mathrm{O}_{4}$. This material acts as a heterogeneous catalyst in a Fenton-like process that degrades the dye Indigo Carmine in water. That is probably due to the presence of $\mathrm{Mn}(\mathrm{III})$ (manganese in the +3 oxidation state) in this material that triggers the decomposition of hydrogen peroxide $\left(\mathrm{H}_{2} \mathrm{O}_{2}\right)$ to yield hydroxyl radicals $\left(\mathrm{HO}^{*}\right)$. Moreover, direct infusion electrospray ionization coupled to high resolution mass spectrometry (ESI-HRMS) was employed to characterize the main by-products resulting from such degradation process. These initial results thus indicate that raw materials from waste batteries can therefore be potentially employed as efficient Fenton-like catalysts to degrade organic pollutants in an aqueous solution.
\end{abstract}

\section{Keywords}

Electronic Waste, Zinc-Carbon Batteries, $\mathrm{ZnMn}_{2} \mathrm{O}_{4}$, Fenton-Like

Degradation, Indigo Carmine, Direct Infusion Electrospray Ionization High 
Resolution Mass Spectrometry, By-Products Identification

\section{Introduction}

The use of electronic devices has been growing continuously worldwide, with increasing consumption of primary (non-rechargeable) and secondary (rechargeable) batteries [1] [2]. The annual consumption of batteries was estimated to be 8 billion units per year in the USA and Europe, 6 billion in Japan, and 1 billion in Brazil [3] [4]. Alkaline and zinc-carbon batteries are primary disposable batteries and one of their main usage is the powering of day-to-day gadgets [5]. After their use, most batteries are discarded as waste. An immediate consequence of the incorrect disposal of e-wastes in the environment is the contamination of the environment by heavy metals, mainly lead, mercury, cadmium and nickel [6]. The recycle of spent batteries is therefore essential not only for environmental safety and human health issues but also for an economic point of view [7] [8]. Thus, many works have been carried out aiming at recovering the metals from these residues, obtaining alloys, nanoparticles with magnetic, adsorbents or catalytic applications [2] [7] [9].

The zinc-carbon battery uses zinc as anode, manganese dioxide as cathode, and an electrolyte of ammonium chloride and/or zinc chloride dissolved in water [10]. As the cell is discharged, the zinc is oxidized and the manganese dioxide is reduced according to a simplified overall cell reaction Equation (1):

$$
\mathrm{Zn}+2 \mathrm{MnO}_{2} \rightarrow \mathrm{Mn}_{2} \mathrm{O}_{3}+\mathrm{ZnO}
$$

Robinson and coworkers [11] compared various manganese oxides, such as $\mathrm{Mn}_{2} \mathrm{O}_{3}, \mathrm{Mn}_{3} \mathrm{O}_{4}$ and $\mathrm{MnO}_{2}$, in the catalytic photochemical oxidation of water to evolve oxygen. They found that the catalytic activities followed the order: $\mathrm{Mn}_{2} \mathrm{O}_{3}>\mathrm{Mn}_{3} \mathrm{O}_{4}>>\mathrm{MnO}_{2}$. Qiu and coworkers [12] synthesized $\mathrm{ZnMn}_{2} \mathrm{O}_{4}$ nanorods by a co-precipitation process. The $\mathrm{ZnMn}_{2} \mathrm{O}_{4}$ nanorods were used as a Fenton-like heterogeneous catalyst for the degradation of methyl violet and its catalytic performances were systematically compared to those of $\mathrm{ZnMnO}_{3}$ nanorods. The results indicated that $\mathrm{ZnMn}_{2} \mathrm{O}_{4}$ nanorods exhibited significantly higher catalytic activity towards the degradation of methyl violet. However, to the best of our knowledge, a detailed study on the reuse of battery residues to obtain $\mathrm{ZnMn}_{2} \mathrm{O}_{4}$ catalysts applied to Fenton-like processes is unprecedented.

This paper aims to collect the anodic paste (comprised mainly by manganese oxides) of discarded zinc-carbon batteries and, after proper treatment and characterization, to test the so-obtained material as a Fenton-like catalyst to degrade organic pollutants in an aqueous medium. Indigo Carmine was chosen as a prototypeanalyte because of its low cost and easy degradation monitoring (via $\mathrm{UV}-\mathrm{V}$ is spectrophotometry). Finally, direct infusion electrospray ionization coupled to high resolution mass spectrometry (ESI-HRMS) is employed to cha- 
racterize the main by-products and, as a consequence, to propose a plausible degradation route for Indigo Carmine under these conditions.

\section{Materials and Methods}

\subsection{Materials and Reagents}

All chemicals were purchased from Sigma-Aldrich (Milwaukee, WI, USA) and used without further purification. Ultrapure water $\left(18 \mathrm{M} \Omega \cdot \mathrm{cm}^{-1}\right.$, Milli-Q system, Millipore, Burlington, Massachusetts, EUA) was used to prepare the solutions.

\subsection{Battery Dismantling}

Discarded batteries were manually dismantled by removing the metallic external cover to access the internal anodic paste. The raw anodic material, a black petrified solid, was grated and triturated in grail and pestle to obtain fine black powder rich in manganese oxides, carbon, zinc, zinc oxides and other trace substances.

\subsection{Anodic Material: Acid Leaching and Calcination}

The black powder anodic material was leached with a sulfuric acid aqueous solution. The purpose of this step was to decrease the content of zinc and other trace substances from the raw anodic material aiming at the attainment of a catalyst with a superior activity. The leaching conditions employed was: sulfuric acid concentration $\left(0.01 \mathrm{~mol} \cdot \mathrm{L}^{-1}\right)$; temperature $\left(60^{\circ} \mathrm{C}\right)$; time $(20 \mathrm{~min})$; ratio of the volume of sulfuric acid solution $(\mathrm{mL})$ per weight $(1 \mathrm{~g})$ of the anodic material $=$ 200. These leaching conditions were employed based on a previous work by Veloso and coworkers [13]. The solid material was isolated upon filtration and dried for $15 \mathrm{~min}$ in an oven and then calcined at $500^{\circ} \mathrm{C}$ for $5 \mathrm{~h}$ in a muffle. After calcination, the material obtained, named CBR (calcined battery residue), possessed a brown color.

\subsection{Characterization}

Analyses by flame atomic absorption spectroscopy (FAAS) were conducted in a Varian Fast AA-240 instrument (Trenton, NJ, USA). A mixture of air/acetylene was employed in all analyses at the following flow rates: air $\left(13.50 \mathrm{~L} \cdot \mathrm{min}^{-1}\right)$ and acetylene $\left(2.00 \mathrm{~L} \cdot \mathrm{min}^{-1}\right)$. For the analyses of zinc and manganese an electrical current of $5 \mathrm{~A}$ was used. For manganese, the reading range was 0 to $4 \mu \mathrm{g} \cdot \mathrm{mL}^{-1}$ with the wavelength set to $279.5 \mathrm{~nm}$ and with a slit of $0.2 \mathrm{~nm}$. For zinc, the reading range, wavelength and slit were set to 0 to $2 \mu \mathrm{g} \cdot \mathrm{mL}^{-1}, 213.9 \mathrm{~nm}$ and 1.0 $\mathrm{nm}$, respectively. Powder X-Ray Diffraction (XRD) experiments were carried out on a ShimadzuXRD-7000 diffractometer (Tokyo, Japan), using $\mathrm{Cu} \mathrm{K} \alpha$ radiation and operating at $40 \mathrm{kV}$ and $40 \mathrm{~mA}$. XRD patterns were collected in the $2 \theta$ range of $10^{\circ}$ to $90^{\circ}$, using a scan velocity of 2.0 degrees $\mathrm{min}^{-1}$. The identification of the crystalline phases was performed using the library Crystallographica SearchMatch, software version 3.0 and the JCPDS (International Centre for Diffraction 
Data $^{\oplus}$ ), file numbers 24-1133 for $\mathrm{ZnMn}_{2} \mathrm{O}_{4}$. Scanning electron microscopy (SEM) analyses were performed in a FEG-Quanta 200 FEI microscope, using an electron voltage of $15.0 \mathrm{kV}$. Samples were sputter-coated with a gold layer of about $5 \mathrm{~nm}$ thickness before the SEM tests. Sorption tests were conducted on a Micromeritcs ASAP 2020 apparatus using nitrogen as adsorbate at $77 \mathrm{~K}$. The sample analyzed was previously degassed at $130^{\circ} \mathrm{C}$ for up to $48 \mathrm{~h}$ under vacuum. The specific surface area (SSA) and pore size distribution were assessed by employing the multipoint Brunauer, Emmett and Teller (BET) and the density functional theory (DFT), respectively.

\subsection{Degradation Experiments}

Degradation tests were carried out in order to check out the activity of the CBR material as a Fenton-like catalyst to degrade Indigo Carmine. Hence, to $50 \mathrm{~mL}$ of an aqueous Indigo Carmine solution (at $30 \mathrm{mg} \cdot \mathrm{L}^{-1}$ ), $50 \mathrm{mg}$ of CBRcatalyst and $0.5 \mathrm{~mL}$ of $\mathrm{H}_{2} \mathrm{O}_{2}\left(\mathrm{CBR} / \mathrm{H}_{2} \mathrm{O}_{2}\right.$ system) were added. The reaction vessel was maintained under magnetic stirring with no heating and $\mathrm{pH}$ control for $120 \mathrm{~min}$. Aliquots of $8 \mathrm{~mL}$ were collected at times of $0,15,30,60$ and $120 \mathrm{~min}$. The resulting suspension was centrifuged for 10 minutes at $4000 \mathrm{rpm}$ in a centrifuge Centribio model 80-2B. The supernatant was then collected and the absorbance of the solution immediately measured at $610 \mathrm{~nm}$ ( $\lambda_{\max }$ for Indigo Carmine) on a UV-VIS spectrophotometer model CARY 50 Conc, Varian. The measurements were made in a quartz cell with an optical length of $1 \mathrm{~cm}$. Adsorption (with the CBR material) and tests with pure hydrogen peroxide $\left(\mathrm{H}_{2} \mathrm{O}_{2}\right)$ were also performed as controls.

\subsection{Direct Infusion ESI-HRMS Analysis}

ESI-HRMS analyses were performed on a hybrid (ion trap-time of flightIT-ToF) mass spectrometer (Shimadzu Corporation) that provides high sensitivity and accuracy with a resolving power over 10.000. The mass spectrometer was equipped with an electrospray ionization (ESI) source operating in the negative $(-3.5 \mathrm{kV})$ mode and with a nebulizer gas $\left(\mathrm{N}_{2}\right)$ at a flow rate of $1.5 \mathrm{~L} \cdot \mathrm{min}^{-1}$. The interface and CDL (curved dessolvation line) were operated at a constant temperature of $200^{\circ} \mathrm{C}$. A mass-to-charge $(\mathrm{m} / \mathrm{z})$ range of 50 - 500 was recorded for each aliquot. The samples $(10 \mu \mathrm{L})$ were directly infused into the ESI source via an autosamplermodel SIL 20AC (Shimadzu Corporation).

\section{Results and Discussion}

\subsection{Characterization of the CBR Material}

Atomic absorption analyses revealed that the CBR material has high contents of $\mathrm{Mn}(44 \% \mathrm{w} / \mathrm{w})$ and $\mathrm{Zn}(23 \% \mathrm{w} / \mathrm{w})$. These data are in agreement with results previously reported in the literature [9] [10]. Such metals are present as oxides, as will be discussed later in this paper. Other components at trace level could also be present in this sample. 
Figure 1 shows the XRD patterns for (a) CBR and (b) hetaerolite, a mineral with a chemical formula of $\mathrm{ZnMn}_{2} \mathrm{O}_{4}$. These data clearly reveal an excellent correlation between the peaks observed in both difractograms. This finding therefore indicates that the chemical composition of the CBR material is essentially $\mathrm{ZnMn}_{2} \mathrm{O}_{4}$, in which manganese is found in an unstable oxidation state, i.e. $\mathrm{Mn}$ (III). Similar results were previously described in the literature [5] [14]. Figure 1 also reveals that these peaks havea thickness close to that of hetaerolite, indicating that CBR is a material with a remarkable crystallinity.

The image by scanning electron microscopy (SEM) shows that the CBR material is quite heterogeneous (Figure 2). Note the presence of grains with varied sizes and shapes. This feature is probably due to the conditions employed in the preparation procedure, which favors the particles coalescence.

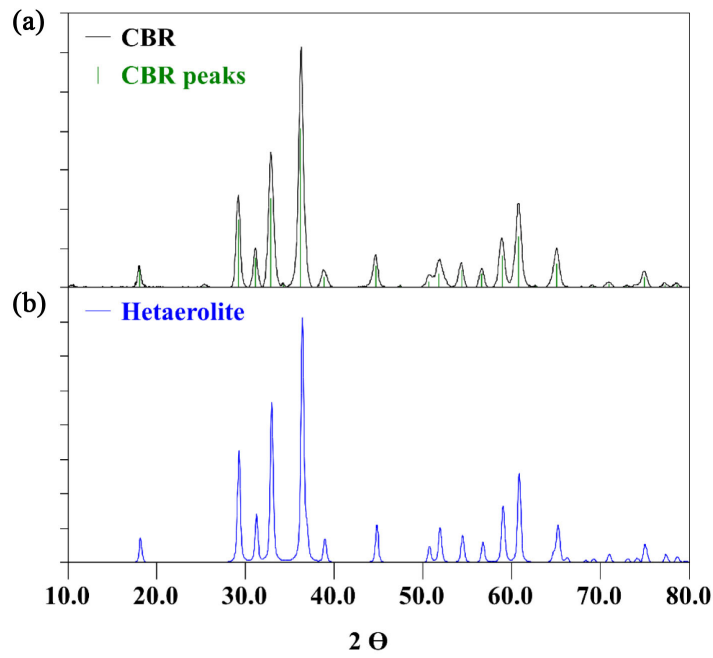

Figure 1. X-ray difractograms of the (a) CBR material and (b) hetaerolite mineral (chemical formula: $\mathrm{ZnMn}_{2} \mathrm{O}_{4}$ ).

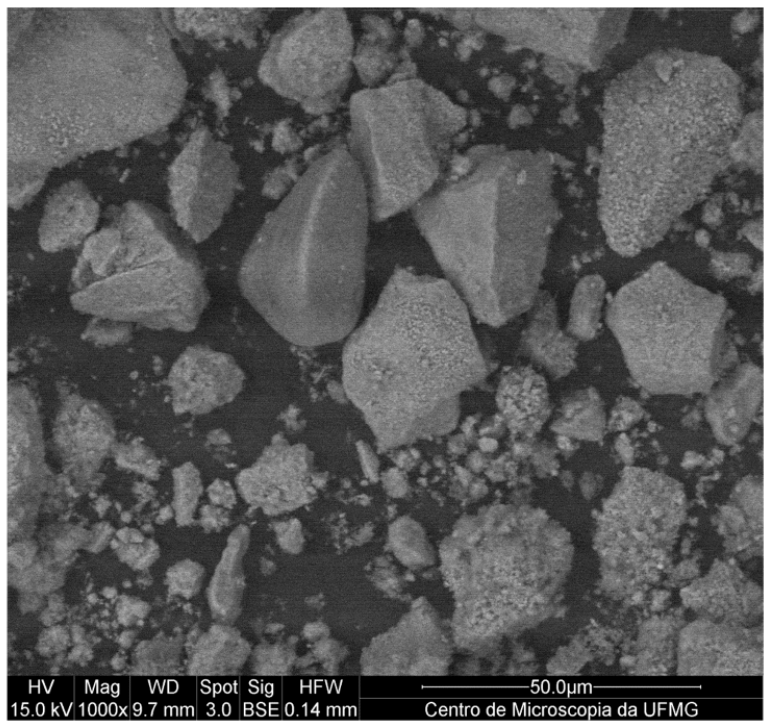

Figure 2. Scanning electron microscopy (SEM) image of the CBR material. 
The CBR material presented negligible specific surface area (SSA) and the isotherms (not shown) are classified as type II, according to IUPAC (International Union of Pure and Applied Chemistry) [15]. This isotherm is characteristic of a non-porous or macroporous adsorbent material. The low SSA is certainly a consequence of the conditions employed in its preparation [16] [17] [18].

\subsection{Fenton-Like Degradation Experiments}

Degradation tests were conducted in order to determine the catalytic efficiency of the CBR material towards the degradation of Indigo Carmine in an aqueous solution. Figure 3 shows the degradation rates produced by the Fenton-like $\left(\mathrm{CBR} / \mathrm{H}_{2} \mathrm{O}_{2}\right.$ ) and controls (CBR and $\mathrm{H}_{2} \mathrm{O}_{2}$ ) systems.

Firstly, results from the control experiments $\left(\mathrm{CBR}\right.$ and $\mathrm{H}_{2} \mathrm{O}_{2}$ ) clearly indicated that the dye Indigo Carmine was removed at very small rates. After 120 min of exposure, the $\mathrm{CBR}$ material removed about $20 \%$ of the dye via adsorption, whereas $\mathrm{H}_{2} \mathrm{O}_{2}$ removed only $10 \%$, probably due to the $\mathrm{H}_{2} \mathrm{O}_{2}$ decomposition that yields hydroxyl radicals. The small adsorption capacity of the $\mathrm{CBR}$ material was expected indeed because of its low SSA. The Fenton-like system $\left(\mathrm{CBR} / \mathrm{H}_{2} \mathrm{O}_{2}\right)$, on the other hand, yielded a much higher degradation rate $(93 \%$ after $120 \mathrm{~min}$ of exposure). These data therefore indicate that the dye degradation is directly induced by the CBR material, which probably acts as a Fenton-like catalyst in the presence of $\mathrm{H}_{2} \mathrm{O}_{2}$. Although the CBR material possesses a too small specific surface area (SSA), the prominent presence of unstable $\mathrm{Mn}(\mathrm{III})$ in its structure favors the formation of hydroxyl radicals ( $\mathrm{HO}^{*}$ ), according to Equation (2) [11] [12]. These extremely-reactive species promptly cause the oxidation of Indigo Carmine, as reported several times elsewhere [19] [20] [21].

$$
\mathrm{Mn}^{3+}+\mathrm{H}_{2} \mathrm{O}_{2} \rightarrow \mathrm{Mn}^{+4}+\mathrm{HO}^{?}+\mathrm{HO}^{-}
$$

\subsection{By-Products Characterization by ESI-HRMS}

Analyzes by direct infusion electrospray ionization mass spectrometry (ESI-MS) was conducted aiming at detecting at least the most abundant by-products resulting from the degradation promoted by the $\mathrm{CBR} / \mathrm{H}_{2} \mathrm{O}_{2}$ system. ESI-MS is a

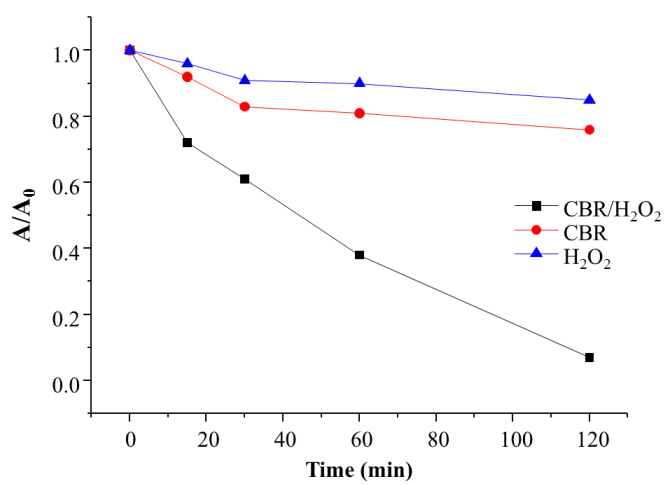

Figure 3. Relative absorbance $\left(\mathrm{A} / \mathrm{A}_{0}\right)$ of Indigo Carmine solutions monitored during exposure to Fenton-like $\left(\mathrm{CBR} / \mathrm{H}_{2} \mathrm{O}_{2}\right)$ and controls $\left(\mathrm{CBR}\right.$ and $\left.\mathrm{H}_{2} \mathrm{O}_{2}\right)$ systems. 
key technique for the identification of by-products resulting from the degradation of water contaminants, and therefore has played an important role in elucidating possible degradation pathways [20] [21]. This technique gently transfers species from the condensed to the gas phase without inducing undesirable side reactions. Because of that, ESI-MS has been successfully applied to monitor an increasing number of environmental processes [19].

Figure 4 shows the mass spectra of aliquots collected after 0 and $120 \mathrm{~min}$ of exposure of an aqueous solution of Indigo Carmine to the $\mathrm{CBR} / \mathrm{H}_{2} \mathrm{O}_{2}$ system. Note that in the mass spectrum of the initial solution (Figure 4(a)) only the ion of $\mathrm{m} / \mathrm{z}$ of 209.9829 , which corresponds to [Indigo Carmine-2H] ${ }^{2-}$ (Indigo Carmine in its doubly-deprotonated form), can be detected. After $120 \mathrm{~min}$, however, the mass spectrum (Figure 4(b)) reveals the absence of this ion, which indicates that Indigo Carmine was fully degraded. This mass spectrum (Figure 4(b)) also displays a number of other ions, some of them ascribed to be the deprotonated forms of degradation products possibly formed under these conditions. Molecular formula for each one of these ions were proposed based on the high-resolution mass spectrometry data, which presented small differences between the experimental and theoretical accurate masses (Table 1).

Other ions, besides the ones displayed in Table 1, are also detected in Figure 4(b) (for instance, $\mathrm{m} / \mathrm{z}$ of 260.8643 and 189.9011). However, reasonable molecular formula with an acceptable error could not be proposed for any of them. These compounds probably leached from the heterogeneous catalyst during the degradation process.

Based on these results as well as on the well-known reactivity of hydroxyl radical towards organic molecules in aqueous medium, a route for the degradation of Indigo Carmine by the $\mathrm{CBR} / \mathrm{H}_{2} \mathrm{O}_{2}$ system could thus be proposed, as outlined in Figure 5. The formation of by-products 2 and $\mathbf{3}$ arising from the oxidation and desulfonation of Indigo Carmine, respectively, has been reported in the literature [19] [20] [21]. It is important to state that in both pathways the determinant participation of hydroxyl radicals is noticeable.

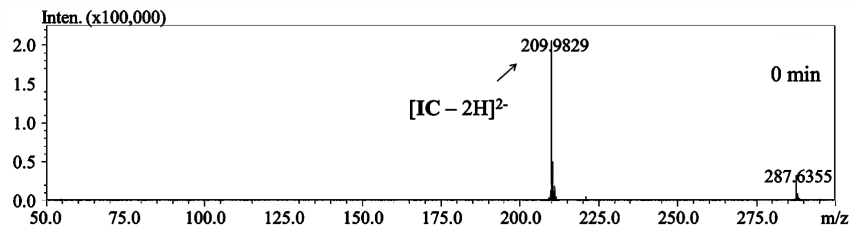

(a)

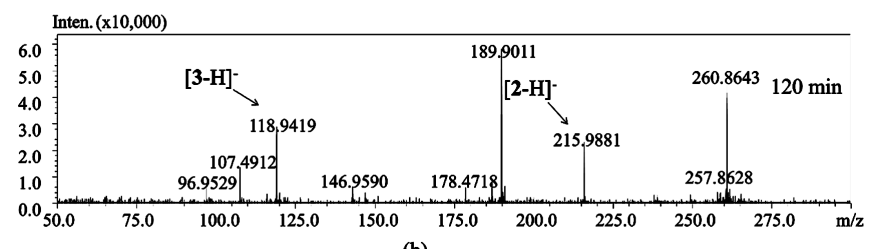

(b)

Figure 4. Mass spectra of two aliquots collected at the following reaction times: (a) 0 min; (b) $120 \mathrm{~min}$. The reaction process refers to the degradation of Indigo Carmine induced by the $\mathrm{CBR} / \mathrm{H}_{2} \mathrm{O}_{2}$ system in an aqueous solution. 


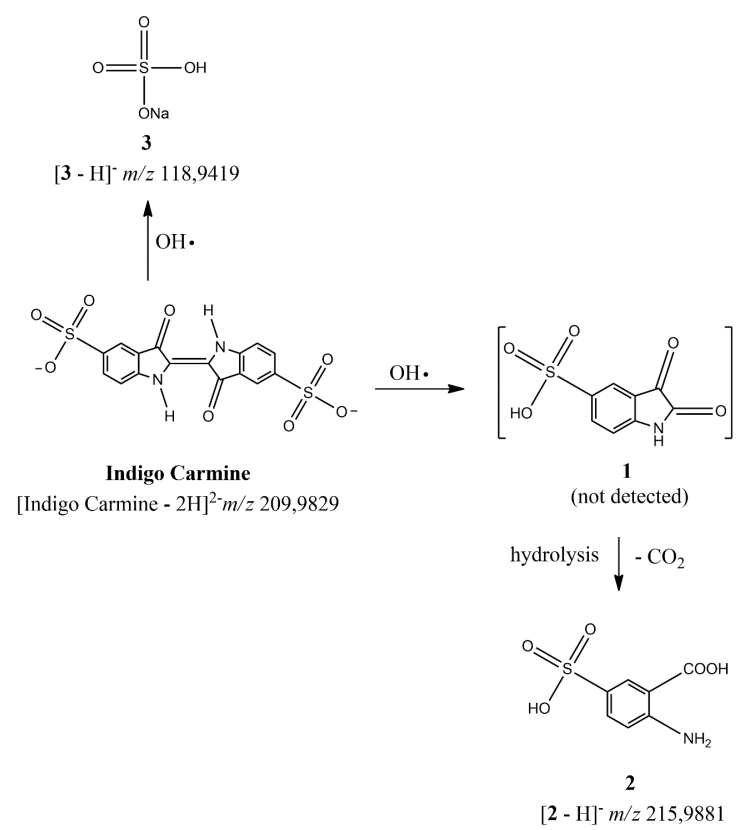

Figure 5. Proposed route for the degradation of Indigo Carmine induced by the CBR/ $\mathrm{H}_{2} \mathrm{O}_{2}$ system in an aqueous solution.

Table 1. High resolution mass spectrometry data used to determine the molecular formula of the degradation products resulting from the exposure of Indigo Carmine to the $\mathrm{CBR} / \mathrm{H}_{2} \mathrm{O}_{2}$ system in an aqueous medium.

\begin{tabular}{cccc}
\hline \multirow{2}{*}{ Compound } & \multicolumn{3}{c}{ Deprotonated Form } \\
\cline { 2 - 4 } & Molecular formula & $\mathbf{m} / \mathbf{z}$ (theoretical) & $\mathbf{m} / \mathbf{z}$ (experimental) \\
\hline Indigo Carmine & {$\left[\mathrm{C}_{16} \mathrm{H}_{8} \mathrm{~N}_{2} \mathrm{O}_{8} \mathrm{~S}_{2}\right]^{2-}$} & 209.9861 & 209.9829 \\
2 & {$\left[\mathrm{C}_{7} \mathrm{H}_{6} \mathrm{NO}_{5} \mathrm{~S}^{-}\right.$} & 215.9967 & 215.9881 \\
$\mathbf{3}$ & {$\left[\mathrm{NaSO}_{4}\right]^{-}$} & 118.9415 & 118.9419 \\
\hline
\end{tabular}

\section{Conclusion}

This work demonstrates that the $\mathrm{ZnMn}_{2} \mathrm{O}_{4}$ catalyst can be obtained from discarded batteries (anodic paste). It acts as an efficient Fenton-like catalyst in the degradation of Indigo Carmine in an aqueous solution. The high efficiency of this catalyst is probably due to the presence of $\mathrm{Mn}(\mathrm{III})$, a quite unstable and reactive species. The interaction of $\mathrm{Mn}(\mathrm{III})$ with $\mathrm{H}_{2} \mathrm{O}_{2}$ generates hydroxyl radicals that are responsible for the high removal of the Indigo Carmine dye from an aqueous medium. It is important to mention that the catalyst was obtained from electronic waste (discarded zinc-carbon batteries). Therefore, in addition to avoiding that such electronic waste becomes a potential source of environmental contamination, this work proposes its use as an efficient remediation agent for water bodies containing organic pollutants. Hence, besides the evident environmental application, this work also presents an economic alternative for the production of new catalysts used in Fenton-like processes. It is noteworthy that this is the first report regarding the attainment of an effective Fenton-like catalyst, 
i.e. $\mathrm{ZnMn}_{2} \mathrm{O}_{4}$, from battery residues. Finally, other possible remediation processes making use of such a promising material are underway in our laboratory.

\section{Acknowledgements}

The authors thank to the Graduate Program of the Department of Chemistry/ Federal University of Minas Gerais and the Brazilian founding agencies (CAPES, CNPq and FAPEMIG) for financial support.

\section{Conflicts of Interest}

The authors declare no conflicts of interest regarding the publication of this paper.

\section{References}

[1] Leite, D.S., Gutierrez Carvalho, P.L., de Lemos, L.R., Barbosa Magestec, A. and Dias Rodrigues, G. (2019) Hydrometallurgical Recovery of Zn(II) and Mn(II) from Alkaline Batteries Waste Employing Aqueous Two-Phase System. Separation and Purification Technology, 210, 327-334. https://doi.org/10.1016/j.seppur.2018.07.038

[2] Ebin, B., Petranikova, M., Steenari, B.-M. and Ekberg, C. (2019) Recovery of Industrial Valuable Metals from Household Battery Waste. Waste Management \& Research, 37, 168-175. https://doi.org/10.1177/0734242X18815966

[3] Dutta, T., et al. (2018) Recovery of Nanomaterials from Battery and Electronic Wastes: A New Paradigm of Environmental Waste Management. Renewable and Sustainable Energy Reviews, 82, 3694-3704. https://doi.org/10.1016/j.rser.2017.10.094

[4] Xu, J., et al. (2008) A Review of Processes and Technologies for the Recycling of Lithium-Ion Secondary Batteries. Journal of Power Sources, 177, 512-527. https://doi.org/10.1016/j.jpowsour.2007.11.074

[5] Ebin, B., Petranikova, M., Steenari, B.-M. and Ekberg, C. (2016) Production of Zinc and Manganese Oxide Particles by Pyrolysis of Alkaline and Zn-C Battery Waste. Waste Management, 51, 157-167. https://doi.org/10.1016/j.wasman.2015.10.029

[6] Rodrigues, G.D., de Lemos, L.R., Mendes da Silva, L.H. and Hespanhol da Silva, M.C. (2013) Application of Hydrophobic Extractant in Aqueous Two-Phase Systems for Selective Extraction of Cobalt, Nickel and Cadmium. Journal of Chromatography $A, 1279,13-19$. https://doi.org/10.1016/j.chroma.2013.01.003

[7] Qu, J., et al. (2015) A New Insight of Recycling of Spent Zn-Mn Alkaline Batteries: Synthesis of $\mathrm{Zn}_{\mathrm{x}} \mathrm{Mn}_{1-\mathrm{x}} \mathrm{O}$ Nanoparticles and Solar Light Driven Photocatalytic Degradation of Bisphenol A Using Them. Journal of Alloys and Compounds, 622, 703-707. https://doi.org/10.1016/j.jallcom.2014.10.166

[8] Lin, H., et al. (2019) Degradation of Bisphenol A by Activating Peroxymonosulfate with $\mathrm{Mn}_{0.6} \mathrm{Zn}_{0.4} \mathrm{Fe}_{2} \mathrm{O}_{4}$ Fabricated from Spent $\mathrm{Zn}-\mathrm{Mn}$ Alkaline Batteries. Chemical Engineering Journal, 364, 541-551. https://doi.org/10.1016/j.cej.2019.01.189

[9] Niu, Z., Zhang, S.K., Ma, M.F., Wang, Z.Y., Zhao, H.Y. and Wang, Y.Y. (2019) Synthesis of Novel Waste Batteries-Sawdust-Based Adsorbent via a Two-Stage Activation Method for $\mathrm{Pb}^{2+}$ Removal. Environmental Science and Pollution Research, 26, 4730-4745. https://doi.org/10.1007/s11356-018-3883-0

[10] Sayilgan, E., Kukrer, T., Civelekoglu, G., Ferella, F., Akcil, A., Veglio, F. and Kitis, M. (2009) A Review of Technologies for the Recovery of Metals from Spent Alkaline 
and Zinc-Carbon Batteries. Hydrometallurgy, 97, 158-166. https://doi.org/10.1016/j.hydromet.2009.02.008

[11] Robinson, D.M., et al. (2013) Photochemical Water Oxidation by Crystalline Polymorphs of Manganese Oxides: Structural Requirements for Catalysis. Journal of the American Chemical Society, 135, 3494-3501. https://doi.org/10.1021/ja310286h

[12] Qiu, M., et al. (2018) $\mathrm{ZnMn}_{2} \mathrm{O}_{4}$ Nanorods: An Effective Fenton-Like Heterogeneous Catalyst with $\mathrm{t}_{2 \mathrm{~g}}{ }^{3} \mathrm{e}_{\mathrm{g}}{ }^{1}$ Electronic Configuration. Catalysis Science \& Technology, 8, 2557-2566. https://doi.org/10.1039/C8CY00436F

[13] Veloso, L.R.S., Carmo Rodrigues, L.E.O., Alvarenga Ferreira, D., Silva Magalhães, F. and Borges Mansur, M. (2005) Development of a Hydrometallurgical Route for the Recovery of Zinc and Manganese from Spent Alkaline Batteries. Journal of Power Sources, 152, 295-302. https://doi.org/10.1016/j.jpowsour.2005.03.133

[14] Konicki, W., Sibera, D. and Narkiewicz, U. (2018) Adsorptive Removal of Cationic Dye from Aqueous Solutions by $\mathrm{ZnO} / \mathrm{ZnMn}_{2} \mathrm{O}_{4}$ Nanocomposite. Separation Science and Technology, 53, 1295-1306. https://doi.org/10.1080/01496395.2018.1444054

[15] Sing, K.S.W. (1982) Reporting Physisorption Data for Gas/Solid Systems with Special Reference to the Determination of Surface Area and Porosity (Provisional). Pure and Applied Chemistry, 54, 2201. https://doi.org/10.1351/pac198254112201

[16] Fang, M., Ström, V., Olsson, R.T., Belova, L. and Rao, K.V. (2012) Particle Size and Magnetic Properties Dependence on Growth Temperature for Rapid Mixed CoPrecipitated Magnetite Nanoparticles. Nanotechnology, 23, Article ID: 145601. https://doi.org/10.1088/0957-4484/23/14/145601

[17] Shalygin, A.S., et al. (2017) The Impact of Si/Al Ratio on Properties of Aluminosilicate Aerogels. Microporous and Mesoporous Materials, 251, 105-113. https://doi.org/10.1016/j.micromeso.2017.05.053

[18] Asamoto, M., Hino, M., Yamaguchi, S. and Yahiro, H. (2011) Transformation of Crystalline Heteronuclear Cyano Complex to Crystalline Perovskite-Type Oxide by Thermal Decomposition. Catalysis Today, 175, 534-540. https://doi.org/10.1016/j.cattod.2011.04.048

[19] Coelho, M.G., et al. (2011) Preparation of a New Composite by Reaction of $\mathrm{SnBu}_{3} \mathrm{Cl}$ with $\mathrm{TiCl}_{4}$ in the Presence of $\mathrm{NH}_{4} \mathrm{OH}$-Photocatalytic Degradation of Indigo Carmine. Applied Organometallic Chemistry, 25, 220-225. https://doi.org/10.1002/aoc.1745

[20] Coelho, M.G., de Lima, G.M., Augusti, R., Maria, D.A. and Ardisson, J.D. (2010) New Materials for Photocatalytic Degradation of Indigo Carmine-Synthesis, Characterization and Catalytic Experiments of Nanometric Tin Dioxide-Based Composites. Applied Catalysis B: Environmental, 96, 67-71. https://doi.org/10.1016/j.apcatb.2010.02.002

[21] de Andrade, F.V., et al. (2012) A Versatile Approach to Treat Aqueous Residues of Textile Industry: The Photocatalytic Degradation of Indigo Carmine Dye Employing the Autoclaved Cellular Concrete/ $\mathrm{Fe}_{2} \mathrm{O}_{3}$ System. Chemical Engineering Journal, 180, 25-31. https://doi.org/10.1016/j.cej.2011.10.089 